\title{
Enhanced adsorption capacity of porous titanium dioxide nanoparticles synthetized in alkaline sol
}

\author{
Luigi Scrimieri ${ }^{1} \cdot$ Luciano Velardi $^{1}$ - Antonio Serra ${ }^{1} \cdot$ Daniela Manno $^{1} \cdot$ Francesca Ferrari $^{2} \cdot$ Maria Cantarella $^{3}$. \\ Lucio Calcagnile $^{1}$
}

Received: 18 August 2020 / Accepted: 21 October 2020 / Published online: 7 November 2020

(c) The Author(s) 2020

\begin{abstract}
In recent years, the exploitation of natural resources and industrial development have led to the production of harmful pollutants. Much of these contaminants end up in water resources, reducing the availability of drinking water. Therefore, it is necessary to find remedies to this situation. Solutions could be the adsorption or the degradation through photocatalysis of these compounds. A good candidate for this task is titanium dioxide $\left(\mathrm{TiO}_{2}\right)$, due to its non-toxicity, stability and low cost. In this work, we propose a novel synthesis of $\mathrm{TiO}_{2}$ nanoparticles (NPs), with high adsorption capacity, produced at low temperature in alkaline environment. Adsorption tests were conducted using methylene blue and diclofenac as model pollutants. Moreover, the obtained NPs have been characterized through Raman spectroscopy, Scanning and Transmission electron microscopies and with thermogravimetric analysis. The results showed a porous structure with a high surface area, able to efficiently adsorb large amounts of dye from the aqueous solution. These properties make the obtained $\mathrm{TiO}_{2}$ powders suitable for applications devoted to the adsorption and recovery of harmful compounds.
\end{abstract}

\section{Graphic abstract}
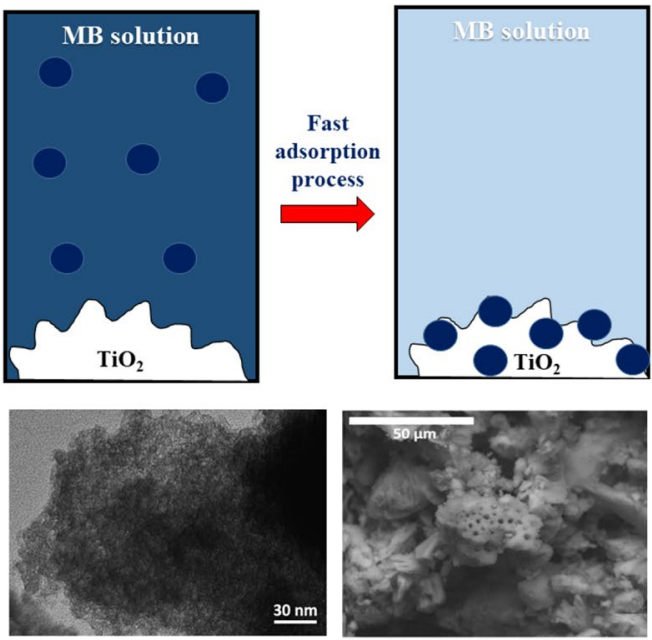

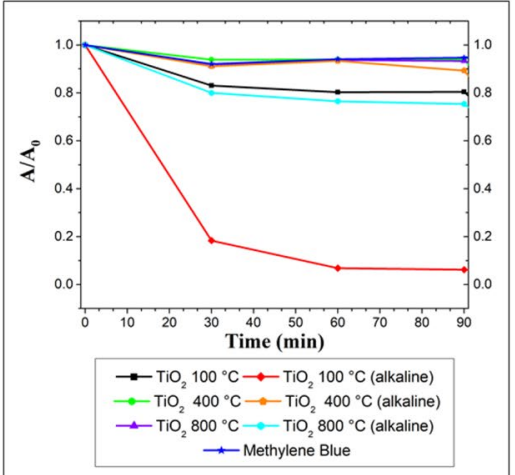

Porous $\mathrm{TiO}_{2}$ nanoparticles with enhanced adsorption capacity

Keywords $\mathrm{TiO}_{2}$ nanoparticles $\cdot$ Adsorption $\cdot$ Porous nano-tubular structure $\cdot$ Methylene blue

\section{Introduction}

Luigi Scrimieri

luigi.scrimieri@unisalento.it

Extended author information available on the last page of the article
Water is an essential element for life. The availability of drinking water is threatened mainly by over-exploitation of water sources and excessive pollution. According to the 
2019 World Health Organization report, in 2017, 29\% of the global population lacked "safely managed drinking water" meaning water at home, available, and safe [1]. Presence of harmful compounds in water is mainly due to industrial, agricultural, and domestic activities [2] and creates problems directly or indirectly to the flora and fauna and consequently also to mankind. Moreover, this type of pollution has negative effects not only on health, but also from a socioeconomic perspective $[3,4]$. Two viable solutions against pollutants are their recovery through porous, high-surface, adsorbent materials that can be easily separated from the reaction environment (e.g., by centrifugation or by fixing it onto a substrate) $[5,6]$ or their neutralization and dissociation via chemical reactions of photocatalysis. Activated carbon, clay minerals, zeolites and polymers are some of the most utilized porous and adsorbent materials [7-9] whereas $\mathrm{TiO}_{2}, \mathrm{ZnO}, \mathrm{CeO}_{2} \mathrm{ZrO}_{2}$ and $\mathrm{WO}_{3}$ are chosen for their photocatalytic activity [10-12], or more in general, in the catalysis of chemical reactions [13-15].

Among the latter, $\mathrm{TiO}_{2}$ has attracted a great interest in the scientific community. This material is chemically stable, non-toxic and low cost [16] and it is used in the degradation of harmful and organic compounds [17-20] through its photoactivity triggered by ultraviolet light (UV), which generates electron-gap pairs responsible for the production of free radicals. Moreover, titanium dioxide is well known also for its mechanical and optical properties [21-23] which are applied in several fields, such as energetic, environmental, antibacterial and material science [24].

It has a compact crystalline structure and exists in three phases: anatase, rutile and brookite. It can be synthesized by several chemical [25-28] and physical [29, 30] techniques in the form of nanoparticles (NPs) [31, 32] and thin films [33-35]. At low calcination temperatures $\left(T_{\mathrm{C}}<400{ }^{\circ} \mathrm{C}\right)$, it is amorphous and exhibits a porous structure but, to our best knowledge, there are no many studies that take into consideration this property for environment applications. $\mathrm{TiO}_{2}$-based materials with adsorption capacity are generally made of composite materials [36-39]. This is also confirmed by a 2018 review analysing titania materials fixed on adsorbent substrates for the production of composite structures [40].

In this work, novel porous $\mathrm{TiO}_{2}$ nanopowders with a high and direct adsorption capacity, prepared by sol-gel method at low temperature $\left(T_{\mathrm{C}}=100{ }^{\circ} \mathrm{C}\right)$ and in an alkaline environment, were produced. We present a fast and simple synthesis of these NPs with an eco-friendly procedure, as it does not use toxic reagents. The chemical structure of the obtained materials has been characterised by Raman spectroscopy, scanning (SEM) and transmission electron (TEM) microscopies and thermogravimetric analysis (TGA) measurements. Methylene blue (MB) and diclofenac have been also used to study the adsorption behaviour of the $\mathrm{TiO}_{2}$ nanoparticles. The results have shown a very high and unusual seizing capacity of MB by the nanoparticles, a photocatalysis-independent phenomenon, due to the porous structure and high surface area of the nanoparticles. This adsorption is shown to be extremely fast and more advantageous than a photocatalysis process.

\section{Materials and synthesis procedure}

The titania $\left(\mathrm{TiO}_{2}\right)$ nanopowders were synthesized by the sol-gel method. All the chemicals used were of reagentgrade purity and were purchased from Sigma-Aldrich. The production of titanium dioxide nanopowders was carried out in alkaline medium, using $\mathrm{NH}_{4} \mathrm{OH}$, and in a neutral water medium as a comparison. In particular, for the alkaline solution preparation, $13.5 \mathrm{ml}$ of $\mathrm{NH}_{4} \mathrm{OH}$ at $28-30 \%$ was added to $10 \mathrm{ml}$ of ultrapure water milliQ. Subsequently, $1.5 \mathrm{ml}$ of Titanium tetraisopropoxide (TTIP) was added to the solution and left in agitation for $60 \mathrm{~min}$ and then kept in dark for $24 \mathrm{~h}$. The obtained precipitate was washed and collected two times with 2-propanol and other two times with ultrapure water, in an orbital shaker. After washing, the products were dried in an oven for $2 \mathrm{~h}$ at $50{ }^{\circ} \mathrm{C}$. Such powders were then thermally treated for $3 \mathrm{~h}$ in a muffle at three different calcination temperatures $T_{\mathrm{C}}=100,450$ and $800{ }^{\circ} \mathrm{C}$. Then, the powder samples were packed into glass holders without any other preparations.

\subsection{Characterization techniques}

Raman spectra were recorded with an InVia spectrometer, manufactured by Renishaw PLC (Gloucestershire, UK), equipped with optical microscope manufactured by Leica (Wetzlar, Germany). The excitation source was the $514.5 \mathrm{~nm}$ output of an $\mathrm{Ar}^{+}$ions laser working at a maximum output power of $25 \mathrm{MW}$. All spectra were recorded using a resolution of $1.5 \mathrm{~cm}^{-1}$ over the spectral range of $150-3000 \mathrm{~cm}^{-1}$ at room temperature. X-Ray diffraction analyses were performed on titania powders, using a Rigaku Miniflex diffractometer, operating in step-scan mode and employing $\mathrm{Cu} \mathrm{K} \alpha$ radiation at $30 \mathrm{kV}$ and $100 \mathrm{~mA}$. The measurements were collected from $10^{\circ}$ to $80^{\circ}$, with a $0.010^{\circ}$ step size and a scan speed of $0.25^{\circ} \mathrm{min}^{-1}$.

SEM images were acquired by the scanning electron microscope JEOL JSM-5410LV with a $\mathrm{Si}(\mathrm{Li})$ windowless detector for the energy-dispersive X-ray microanalysis, an emission source of tungsten filament $(\mathrm{W})$, a resolution of $3.5 \mathrm{~nm}$, a magnification of 100-200,000 $\times$ and an acceleration voltage of $0.5-30 \mathrm{kV}$. The samples were observed at low-vacuum mode, avoiding any kind of polishing and without covering by a conductive layer. Analysis was processed using Link Isis software by Oxford Instruments and Image Pro-Plus by Media Cybernetics. 
TEM images of $\mathrm{TiO}_{2}$ materials were taken using Hitachi 7700 transmission electron microscope operated at $100 \mathrm{kV}$. This acceleration voltage was settled to obtain a sufficient resolution and minimal radiation damage of the material. Specimens for TEM observations were prepared by dropcasting of freshly solutions containing $\mathrm{TiO}_{2}$ nanoparticles onto standard carbon supported 600-mesh copper grid and drying slowly in air naturally.

Thermogravimetric analysis was used to monitor the mass variation of the titania powder samples. The system checks weight loss in function of time or temperature. The apparatus consisted of a Simultaneous Thermal Analyzer STA 409 by NETZSCH. Tests required a temperature ramp from 10 to $1100{ }^{\circ} \mathrm{C}$, with a heating rate of $10^{\circ} \mathrm{C} / \mathrm{min}$. Each sample was measured three times. The analysis was conducted in air atmosphere. The degradation rate can be known if the tangent at the curve is traced.

\subsection{Adsorption tests}

Adsorption tests were carried out on samples of $\mathrm{TiO}_{2}$ powders prepared in neutral and alkaline $\mathrm{pH}$ condition. The adsorption properties of the samples were evaluated by studying the variation in the methylene blue concentration in aqueous medium spectrophotometrically (using a PerkinElmer Lambda $45 \mathrm{UV}-\mathrm{Vis}$ spectrophotometer) via the solution absorbance in the Lambert-Beer regime. A quantity of $2.5 \mathrm{mg}$ of $\mathrm{TiO}_{2}$ nanopowder was dispersed in $2 \mathrm{ml}$ of the MB solution with a starting concentration of $1.5 \times 10^{-5} \mathrm{M}$. Another test was conducted with diclofenac. Also in this case, $2.5 \mathrm{mg}$ of $\mathrm{TiO}_{2}$ nanopowder was dispersed in $2 \mathrm{ml}$ of diclofenac solution at a concentration of $1 \times 10^{-4} \mathrm{M}$. The absorbance $(A)$ of the solutions was measured at regular intervals $(30 \mathrm{~min})$, until the adsorption equilibrium was reached, recovering a fraction of the solution after centrifuging. Adsorption was studied monitoring the peak absorption of the MB at $665 \mathrm{~nm}$ and the peak absorption of diclofenac at $276 \mathrm{~nm}$. Results are reported as $A / A_{0}$, where $A_{0}$ is the absorbance value of the solution a $t=0 \mathrm{~min}$.

\section{Results and discussion}

\subsection{Raman characterization}

Raman spectra are reported in Fig. 1. The analysis revealed the typical active modes of anatase for the samples prepared in a neutral medium and calcinated at $100^{\circ} \mathrm{C}$ and $400{ }^{\circ} \mathrm{C}$. The peaks were observed at $151,403,518$ and $639 \mathrm{~cm}^{-1}$ for the powder treated at $100{ }^{\circ} \mathrm{C}$ and at $144,397,516$ and $636 \mathrm{~cm}^{-1}$ for that at $400{ }^{\circ} \mathrm{C}$, and are attributed [41] to the vibration symmetries $E_{\mathrm{g}}, B_{1 \mathrm{~g}}, A_{1 \mathrm{~g}} / B_{1 \mathrm{~g}}$ and $E_{\mathrm{g}}$, respectively. The active mode shift at $151 \mathrm{~cm}^{-1}$ observed in the sample

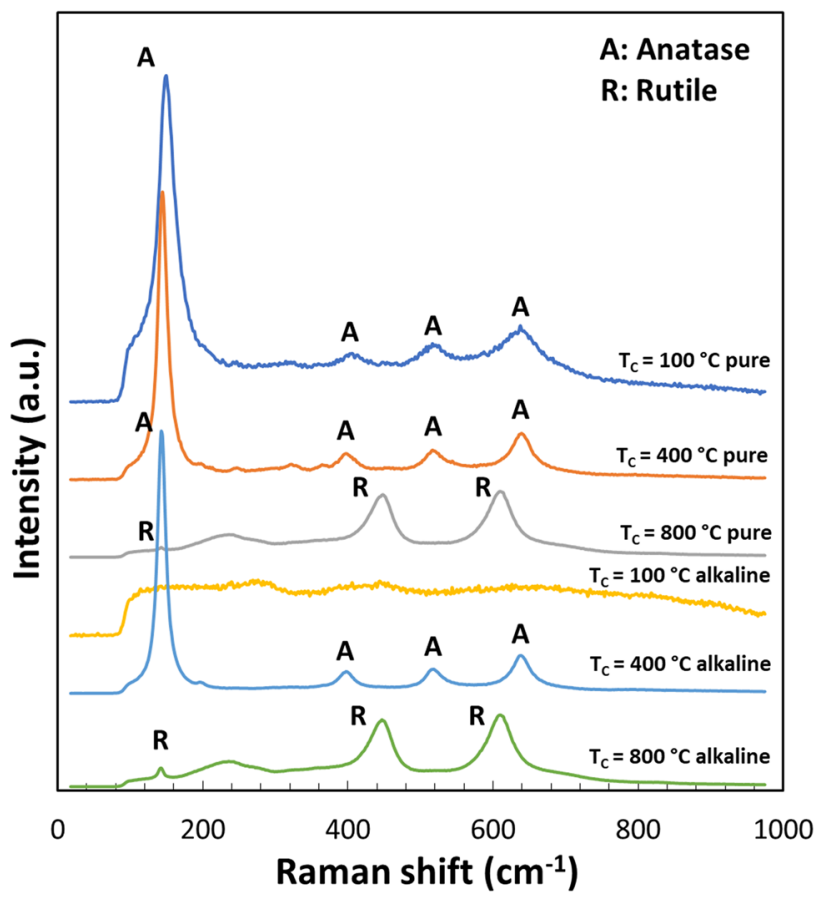

Fig. 1 Raman spectra of $\mathrm{TiO}_{2}$ nanopowders prepared in neutral and alkaline media and treated at calcination temperatures $\left(T_{\mathrm{C}}\right)$ of 100 , 400 and $800{ }^{\circ} \mathrm{C}$. The letters $\mathrm{A}$ and $\mathrm{R}$ indicate the anatase and rutile phases, respectively

treated at $100{ }^{\circ} \mathrm{C}$ in neutral medium could be related to low crystallinity and to the presence of oxygen vacancies in the $\mathrm{TiO}_{2}$ structure, as reported in literature $[42,43]$. The samples treated at the highest temperature $\left(T_{\mathrm{C}}=800{ }^{\circ} \mathrm{C}\right)$ showed three optical phonon peaks of the rutile phase: a very low-intensity mode centred at $143 \mathrm{~cm}^{-1}$ and two highintensity modes at 446 and $609 \mathrm{~cm}^{-1}$, related to the $B_{1 \mathrm{~g}}, E_{\mathrm{g}}$ and $A_{1 \mathrm{~g}}$ symmetries, respectively. The band observed around $235 \mathrm{~cm}^{-1}$ is generally attributed to the two-photon scattering [44].

Both $\mathrm{TiO}_{2}$ nanoparticles synthesized in neutral and alkaline environments showed similar structures at the Raman analysis. Only the powder treated at $100{ }^{\circ} \mathrm{C}$ and prepared in alkaline solution showed a strong amorphous structure, probably induced by the sol (nitrogen was introduced during the sol-gel preparation as ammonium) and by the low temperature, inadequate to induce the crystallization of the titanium dioxide. On the other hand, temperatures of $400{ }^{\circ} \mathrm{C}$ and $800{ }^{\circ} \mathrm{C}$ were sufficient to induce the crystallization (anatase and rutile, respectively) in the same basic environment.

\subsection{TEM and SEM analyses}

To study the morphology of nanoparticles, TEM and SEM observations of the nanopowders prepared in neutral and alkaline conditions and thermally treated at $100{ }^{\circ} \mathrm{C}$ and 
$400{ }^{\circ} \mathrm{C}$ were carried out. Under the transmission microscope, the alkaline low-temperature sample appeared as very thin sheets folded and/or rolled up along the edges (Fig. 2a). On the contrary, the sample prepared in neutral environment at low temperature (Fig. 2b) showed a granular structure typical of sol-gel synthesis.

In addition, the increase in temperature $\left(T_{\mathrm{C}}=400{ }^{\circ} \mathrm{C}\right)$ induced a drastic change in the nanoparticles morphology. The powders synthesized in neutral or alkaline environments developed, instead, a granular structure (Fig. 3a, b). We founded the same result at the highest temperature $\left(T_{\mathrm{C}}\right.$ $=800{ }^{\circ} \mathrm{C}$ ) (images are not reported here).

The structure of the alkaline sample treated at $100{ }^{\circ} \mathrm{C}$, observed at TEM, was studied in detail at SEM. Under the scanning microscope, nanoparticles revealed a highly porous nano-tubular structure (Fig. 4a-c).

SEM and TEM analyses confirmed the extremely porous nature of the $\mathrm{TiO}_{2}$ NPs with a large surface area.
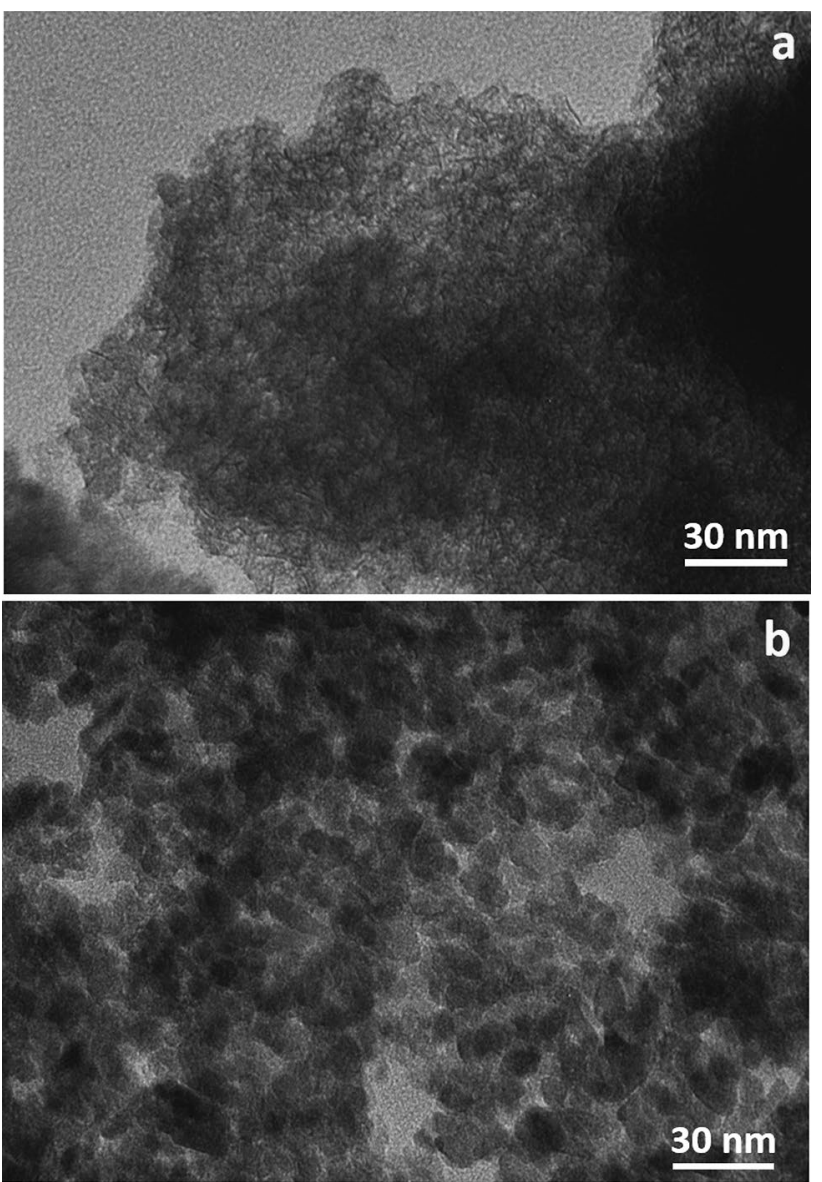

Fig. 2 TEM images of $\mathrm{TiO}_{2}$ nanoparticles prepared in alkaline (a) and neutral (b) environments, treated at temperature of $100{ }^{\circ} \mathrm{C}$
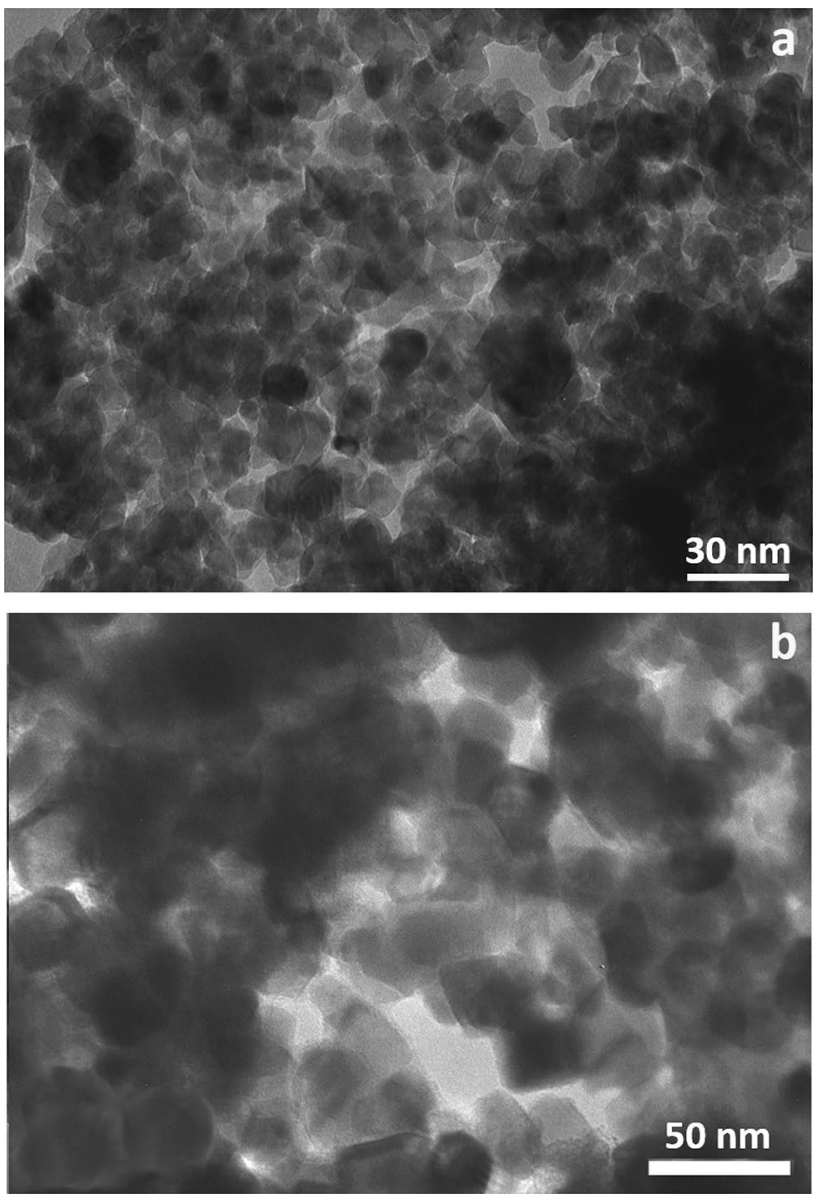

Fig. 3 TEM images of $\mathrm{TiO}_{2}$ nanoparticles prepared in alkaline (a) and neutral (b) environments, treated at temperature of $400^{\circ}$

\subsection{Thermogravimetic analysis}

Thermogravimetric analysis tests were carried out to study the mass variation as a function of the temperature and to indirectly acquire information regarding the surface area of the nanoparticles. Generally, a mass variation, observed in an incompatible temperature range with the phase transition temperature, may be related to desorption of molecules from the surface of the material, so the greater the change in mass, the greater the surface area of the material. The measurements were conducted on $\mathrm{TiO}_{2}$ powders prepared in neutral and alkaline environments at different temperatures $\left(T_{\mathrm{C}}=100,400\right.$ and $\left.800{ }^{\circ} \mathrm{C}\right)$. The samples were heated up to $1100{ }^{\circ} \mathrm{C}$ and the mass variation vs temperature was measured. The resulting graphs are displayed in Fig. 5. Samples calcined at $800{ }^{\circ} \mathrm{C}$ did not highlight a change in mass, while those calcined at $400{ }^{\circ} \mathrm{C}$ showed only a slight decrease in mass $(<5 \%)$. Only the powders dried during preparation at $100{ }^{\circ} \mathrm{C}$, revealed a greater decrease in mass: in particular, we found a mass loss of about $10 \%$ for those prepared in neutral environment and a more consistent decrease of $22.5 \%$ for the 

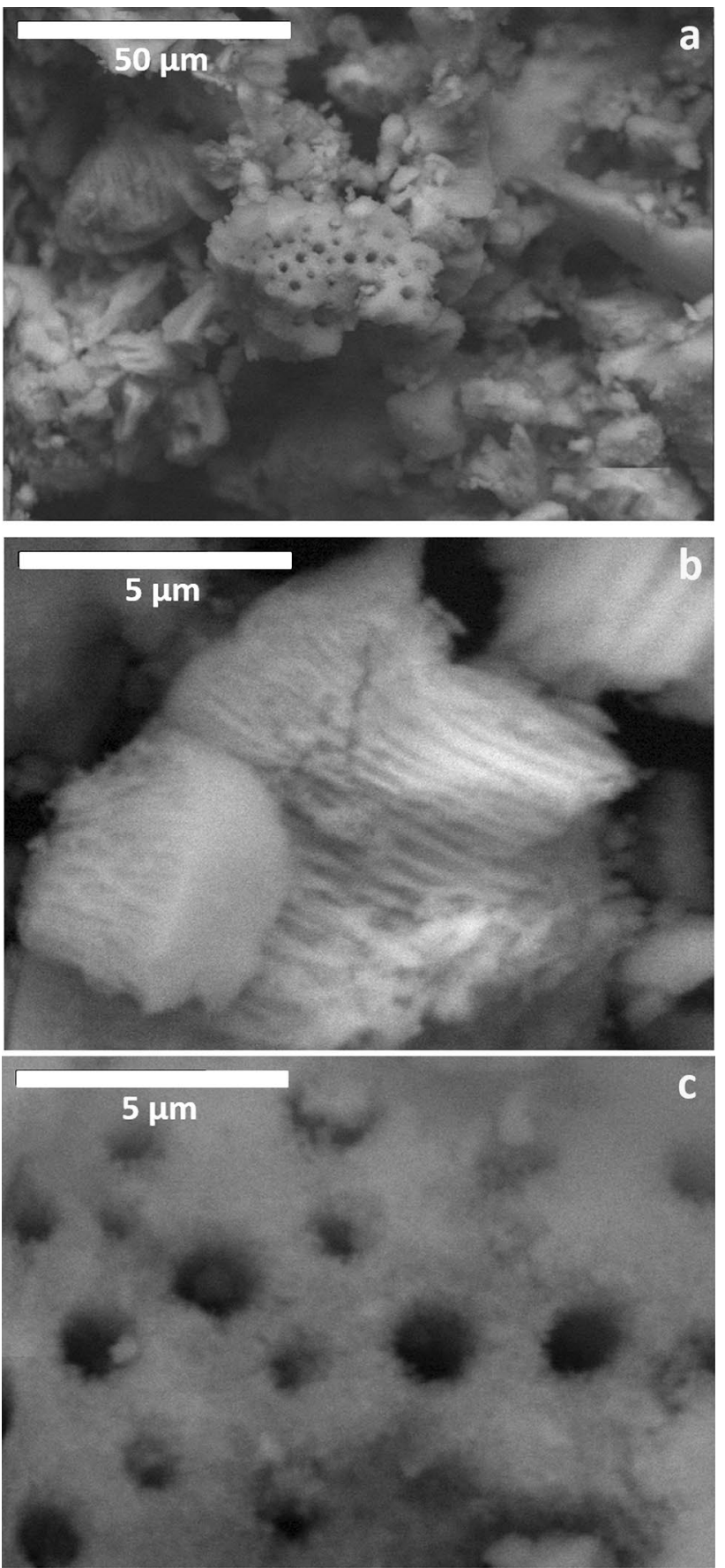

Fig. 4 a SEM images of $\mathrm{TiO}_{2}$ nanoparticles prepared in alkaline environments, treated at the temperature of $100{ }^{\circ} \mathrm{C} ; \mathbf{b}$ and $\mathbf{c}$ details of tubular structures with higher magnification

samples synthetized in alkaline medium. The mass variation occurred at temperatures in range between 20 and $200{ }^{\circ} \mathrm{C}$, in which the molecules, such as water adsorbed to the surface [45], pass into the gas phase reducing the mass of the sample. Therefore, the change in mass is due to desorption of molecules from the surface and not to a phase change of titanium dioxide, which occurs at higher temperatures [46].

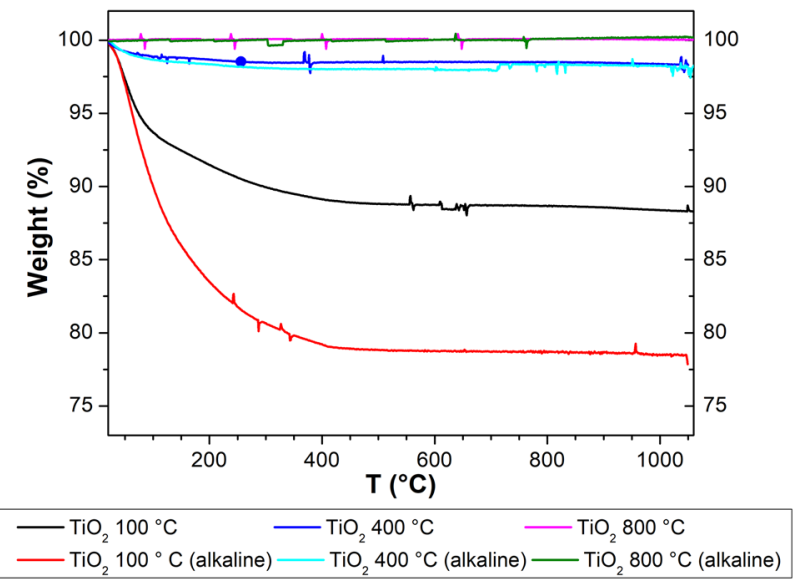

Fig. 5 Thermogravimetric analysis of $\mathrm{TiO}_{2}$ powders synthetized in neutral and alkaline environments at different temperatures $\left(T_{\mathrm{C}}\right.$ $=100,400$ and $800{ }^{\circ} \mathrm{C}$ )

These results were in accordance with the high surface area observed by electron microscopy analyses.

\subsection{Adsorption tests}

Figure 6 shows the $\mathrm{MB}$ absorption kinetics of $\mathrm{TiO}_{2}$ nanopowders prepared in neutral and alkaline media, calcinated at different temperatures $\left(T_{\mathrm{C}}=100,400,800{ }^{\circ} \mathrm{C}\right)$. The graph shows the absorbance values normalized with respect to the initial value $\left(A / A_{0}\right)$, as a function of time. All samples reached the adsorption equilibrium after about $30 \mathrm{~min}$. Only

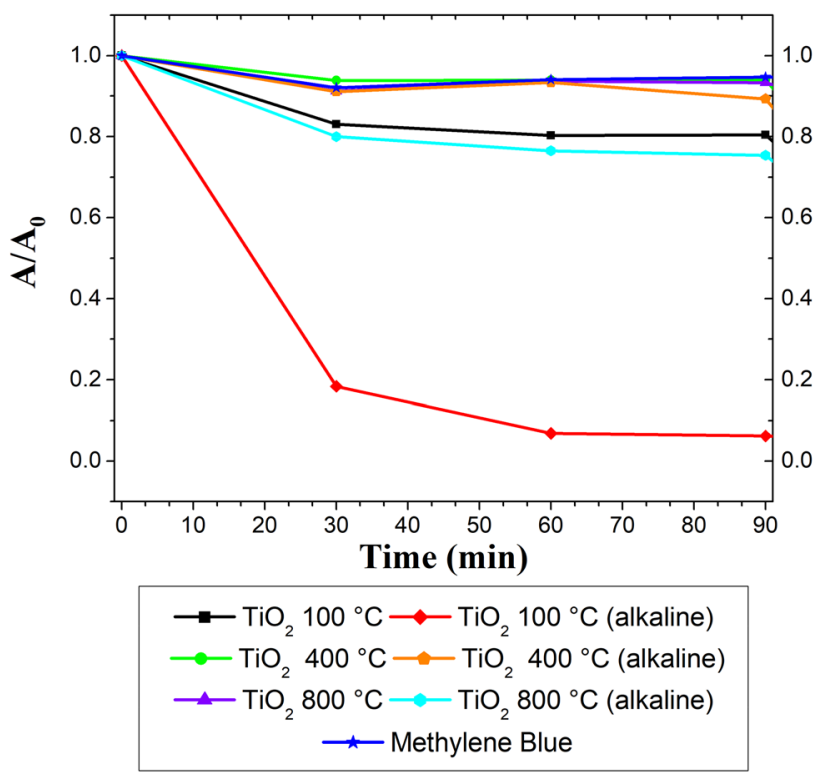

Fig. 6 Methylene blue adsorption kinetics of $\mathrm{TiO}_{2}$ powders synthetized in neutral and alkaline media, calcinated at different temperatures $\left(T_{\mathrm{C}}=100,400,800^{\circ} \mathrm{C}\right)$ 
one sample revealed a different behaviour from the others. Differently from the others, the nanopowder prepared in alkaline environment and calcinated at $100{ }^{\circ} \mathrm{C}$ showed a rapid drop in the absorbance value of the solution, "decolorizing" it in a few minutes.

It was, therefore, studied in detail the kinetics of adsorption of this sample. To achieve the sample saturation, the solution was centrifuged, and the liquid phase was recovered. Subsequently, the nanopowder was dispersed in a fresh MB solution. Once again, the powder showed a rapid adsorption of the dye, completely absorbing the MB within $30 \mathrm{~min}$. This effect was then studied for several times and, only after 12 cycles, the phenomenon demonstrated a slowdown, as shown in Fig. 7.

The strong adsorption of the dye may be due to an effect of opposite surface charge, which guarantees the attraction between organic molecule and $\mathrm{TiO}_{2}$, to a high surface area of titania NPs or to a synergistic effect of these two factors. To understand the charge influence on the adsorption, a test with diclofenac (a molecule with an opposite charge to MB) was carried out.

Figure 8 shows the absorption kinetics of this molecule on $\mathrm{TiO}_{2}$ powder prepared at $100{ }^{\circ} \mathrm{C}$ in basic $\mathrm{pH}$ environment. In this case, the adsorption resulted much more limited and the system reached the equilibrium after $230 \mathrm{~min}$. Therefore, the charge of the target molecule seems to play a role in this phenomenon.

The obtained results are very interesting and have been compared with literature. Table 1 shows the adsorption performance comparison between our material and two found in recent papers. The comparison takes into account the different starting conditions in terms of concentration, amount of $\mathrm{TiO}_{2}$ used and exposure time. The $\mathrm{TiO}_{2}$ described in

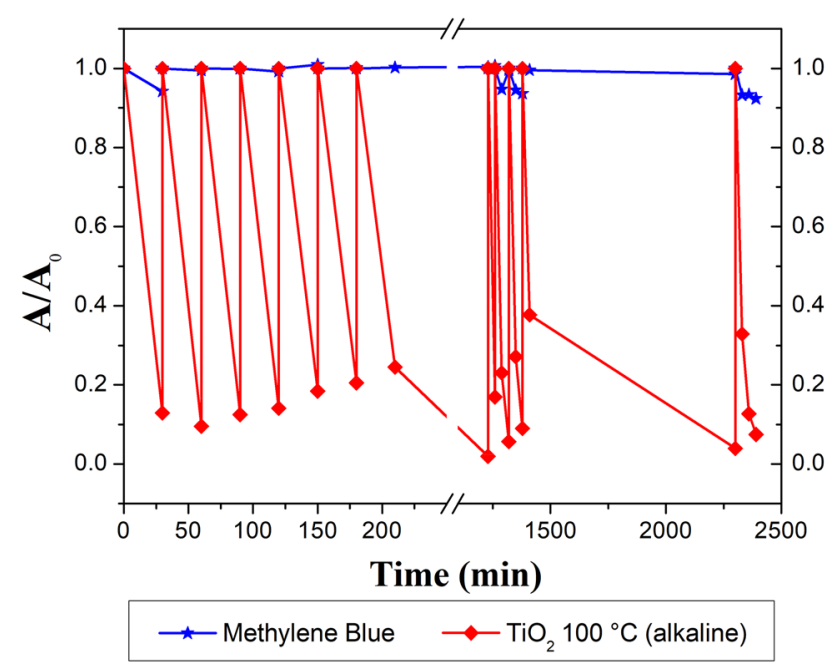

Fig. 7 Methylene blue adsorption of $\mathrm{TiO}_{2}$ powder prepared at $T_{\mathrm{C}}=100{ }^{\circ} \mathrm{C}$ in basic $\mathrm{pH}$ environment

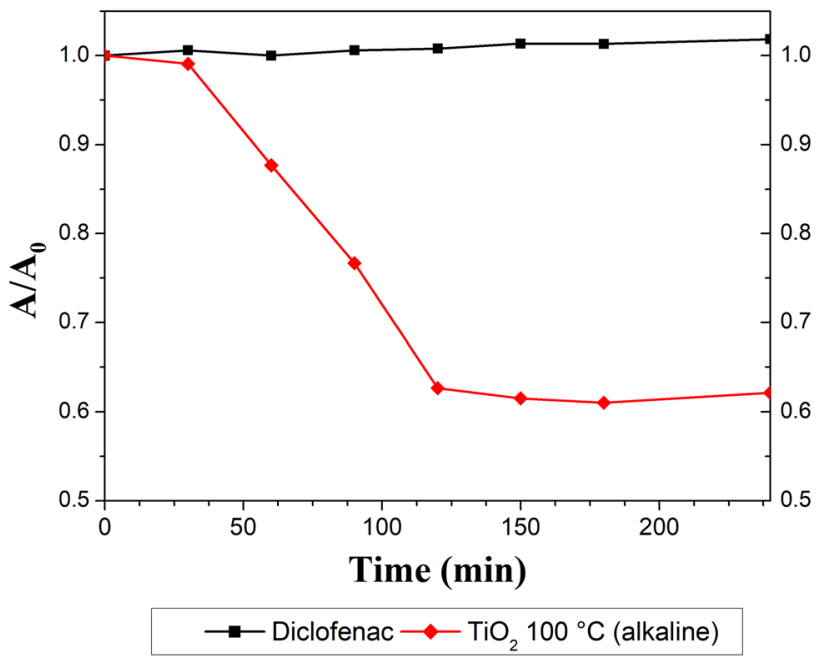

Fig. 8 Diclofenac adsorption kinetics of $\mathrm{TiO}_{2}$ powder prepared at $100{ }^{\circ} \mathrm{C}$ in basic $\mathrm{pH}$ environment

our work is capable of absorbing a good amount of dye in $30 \mathrm{~min}$. This quantity is even greater taking into account that, after $30 \mathrm{~min}$, the sample has not reached the saturation and, therefore, several cycles are needed to reach it, bringing the absorbed amount to rather high values.

\section{Conclusion}

In this work, $\mathrm{TiO}_{2} \mathrm{NPs}$ with high adsorption capacity were synthetized with a simple and eco-friendly procedure. The powder prepared in basic environment and at low temperature $\left(T_{\mathrm{C}}=100{ }^{\circ} \mathrm{C}\right)$ revealed a more complex and porous structure than other nanoparticles synthesized in neutral environment. TEM and SEM analyses highlighted also a high surface area. In addition, these nanoparticles showed a good affinity for methylene blue rather than diclofenac, indicating that the extreme adsorbing capacity founded is due to the synergistic effect of surface charge and surface area. According to these considerations, these titania-based materials can be effectively applied in the context of adsorption and recovery of pollutants from wastewaters.

Funding Open access funding provided by Università del Salento within the CRUI-CARE Agreement.

Open Access This article is licensed under a Creative Commons Attribution 4.0 International License, which permits use, sharing, adaptation, distribution and reproduction in any medium or format, as long as you give appropriate credit to the original author(s) and the source, provide a link to the Creative Commons licence, and indicate if changes were made. The images or other third party material in this article are included in the article's Creative Commons licence, unless indicated otherwise in a credit line to the material. If material is not included in 
Table 1 Adsorption performance comparison

\begin{tabular}{|c|c|c|c|c|}
\hline Reference (year) & Adsorber & $\mathrm{mg}$ of $\mathrm{MB} / \mathrm{mg}$ of adsorber & Time (min) & Comment \\
\hline Geng et al. [47] (2018) & $\mathrm{TiO}_{2}$ and alum sludge & 0.0267 & 60 & \\
\hline Mohammadi, et al. [48] (2017) & $\begin{array}{l}\text { 5-Sulfosalicylic acid } \\
\text { grafted } \mathrm{TiO}_{2}(5-\mathrm{SA}- \\
\left.\mathrm{TiO}_{2}\right)\end{array}$ & 0.0048 & 150 & $\begin{array}{l}\text { Best sample absorbs only } 60 \% \text { of } \\
\text { the initial MB }(0.008 \mathrm{mg})\end{array}$ \\
\hline Our study & $\begin{array}{l}\mathrm{TiO}_{2} \text { NPs synthetized in } \\
\text { alkaline sol }\end{array}$ & 0.0096 (unsaturated) & 30 (one cycle) & After 12 cycles 0.1152 (saturated) \\
\hline
\end{tabular}

the article's Creative Commons licence and your intended use is not permitted by statutory regulation or exceeds the permitted use, you will need to obtain permission directly from the copyright holder. To view a copy of this licence, visit http://creativecommons.org/licenses/by/4.0/.

\section{References}

1. Unicef, World Health Organization. Progress on household drinking water, sanitation and hygiene 2000-2017: Special focus on inequalities. 2019

2. P.A.G.M. Scheren, H.A. Zanting, A.M.C. Lemmens, Estimation of water pollution sources in Lake Victoria, East Africa: application and elaboration of the rapid assessment methodology. J. Environ. Manage. 58(4), 235-248 (2000)

3. A. Ebenstein, The consequences of industrialization: evidence from water pollution and digestive cancers in China. Rev. Econ. Stat. 94(1), 186-201 (2012)

4. Z. Garba, Domestic water pollution among local communities in Nigeria-causes and consequences. Eur. J. Sci. Res. 52(4), 592-603 (2011)

5. L. Li, B. Li, L. Wu, X. Zhao, J. Zhang, Magnetic, superhydrophobic and durable silicone sponges and their applications in removal of organic pollutants from water. Chem. Commun. 50, 7831-7833 (2014)

6. P. Samanta, A.V. Desai, S. Let, S.K. Ghosh, Advanced porous materials for sensing, capture and detoxification of organic pollutants toward water remediation. ACS Sustain. Chem. Eng. 7(8), 7456-7478 (2019)

7. Q.U. Jiuhui, Research progress of novel adsorption processes in water purification: a review. J. Environ. Sci. 20, 1-13 (2008)

8. J. Wang, Y. Xu, B. Ding, Z. Chang, X. Zhang, Y. Yamauchi, K.C.W. Wu, Confined self-assembly in two-dimensional interlayer space: monolayered mesoporous carbon nanosheets with in-plane orderly arranged mesopores and a highly graphitized framework. Angew. Chem. Int. Ed. 57(11), 2894-2898 (2018)

9. E. Doustkhah, J. Lin, S. Rostamnia, C. Len, R. Luque, X. Luo, Y. Bando, K.C.-W. Wu, J. Kim, Y. Yamauchi, Y. Ide, Development of sulfonic-acid-functionalized mesoporous materials: synthesis and catalytic applications. Chem. Eur. J. 25(7), 1614-2163 (2019)

10. H. Ren, P. Koshy, W. Chen, S. Qi, C.C. Sorrell, Photocatalytic materials and technologies for air purification. J. Hazard. Mater. 325, 340-366 (2017)

11. C.C. Lee, C.L. Chen, Y.T. Liao, K.C.W. Wu, C.C. Chueh, Enhancing efficiency and stability of photovoltaic cells by using perovskite/Zr-MOF heterojunction including bilayer and hybrid structures. Adv. Sci 6(5), 1801715 (2019)

12. C.-C. Chueh, C. Chen, Y. Su, H. Konnerth, Y. Gu, C. Kung, K.C.-W. Wu, Harnessing MOF materials in photovoltaic devices: recent advances, challenges, and perspectives. J Mat. Chem. A. 7, 17079-17095 (2019)
13. Y. Liao, B.M. Matsagar, K.C.-W. Wu, Metal-organic framework (MOF)-derived effective solid catalysts for valorization of lignocellulosic biomass. ACS Sustain. Chem. Eng. 6(11), 13628-13643 (2018)

14. H. Konnerth, B.M. Matsagar, S.S. Chen, M.H.G. Prechtl, F.-K. Shieh, K.C.-W. Wu, Metal-organic framework (MOF)-derived catalysts for fine chemical production. Coord. Chem. Rev 416, 213319 (2020)

15. Y. Liao, V.C. Nguyen, N. Ishiguro, A.P. Young, C. Tsung, K.C.-W. Wu, Engineering a homogeneous alloy-oxide interface derived from metal-organic frameworks for selective oxidation of 5-hydroxymethylfurfural to 2,5-furandicarboxylic acid. Appl. Catal. B 270, 118805 (2020)

16. F. Madjene, L. Aoudjit, S. Igoud, H. Lebik, B. Boutra, A review: titanium dioxide photocatalysis for water treatment. Trans. J. Sci. Technol. 3(10), 1857-8047 (2013)

17. K. Xiaolan, L. Sihang, D. Zideng, H. Yunping, S. Xuezhi, T. Zhenquan, Titanium dioxide: from engineering to applications. Catalysts 9(2), 191 (2019)

18. A. Fujishima, X. Zhang, D.A. Tryk, $\mathrm{TiO}_{2}$ photocatalysis and related surface phenomena. Surf. Sci. Rep. 63, 515-582 (2008)

19. Y. Lee, S. Lee, H.S. Kim, J.T. Moon, J.B. Joo, I. Choi, Multifunctional and recyclable $\mathrm{TiO}_{2}$ hybrid sponges for efficient sorption, detection, and photocatalytic decomposition of organic pollutants. J. Ind. Eng. Chem. 73, 328-335 (2019)

20. A. Fujishima, K. Honda, Electrochemical photolysis of water at a semiconductor electrode. Nature 238, 37 (1972)

21. V.C. Gudla, F. Jensen, A. Simar, R. Shabadi, R. Ambat, Friction stir processed $\mathrm{Al}-\mathrm{TiO}_{2}$ surface composites: anodising behaviour and optical appearance. Appl. Surf. Sci. 324, 554-562 (2015)

22. V.C. Gudla, V.E. Johansen, S. Canulescu, J. Schou, R. Ambat, Simulation of reflectance from white-anodised aluminium surfaces using polyurethane- $\mathrm{TiO}_{2}$ composite coatings. J. Mater. Sci. 50, 4565-4575 (2015)

23. R.U. Din, V.C. Gudla, M.S. Jellesen, R. Ambat, Microstructure and corrosion performance of steam-based conversion coatings produced in the presence of $\mathrm{TiO}_{2}$ particles on aluminium alloys. Surf. Coat. Technol. 296, 1-12 (2016)

24. X. Chen, S.S. Mao, Titanium dioxide nanomaterials: synthesis, properties, modifications, and applications. Chem. Rev. 107(7), 2891-2959 (2007)

25. B.K. Mutuma, G.N. Shao, W.D. Kim, H.T. Kim, Sol-gel synthesis of mesoporous anatase-brookite and anatase-brookite-rutile $\mathrm{TiO}_{2}$ nanoparticles and their photocatalytic properties. J. Colloid Interface Sci. 442, 1-7 (2015)

26. T. Kalaivani, P. Anilkumar, Role of temperature on the phase modification of $\mathrm{TiO}_{2}$ nanoparticles synthesized by the precipitation method. Silicon 10(4), 1679-1686 (2018)

27. C.C. Wang, J.Y. Ying, Sol-gel synthesis and hydrothermal processing of anatase and rutile titania nanocrystals. Chem. Mater. 11, 3113 (1999) 
28. S. Seifried, M. Winterer, H. Hahn, Nanocrystalline titania films and particles by chemical vapor synthesis. Chem. Vap. Depos. 6, 239 (2000)

29. H.M. Smith, A.F. Turner, Vacuum deposited thin films using a ruby laser. Appl. Opt. 4(1), 147 (1965)

30. L. Velardi, L. Scrimieri, G. Vasco, A. Serra, D. Manno, V. Nassisi, L. Calcagnile, G. Quarta, Nickel doped $\mathrm{TiO}_{2}$ films by a modified laser plasma source for photocatalytic applications. J. Inst. 15, C03039 (2020)

31. A. Nath, S.S. Laha, A. Khare, Synthesis of $\mathrm{TiO}_{2}$ nanoparticles via laser ablation at titanium-water interface. Integr. Ferroelectr. 121(1), 58 (2010)

32. L. Velardi, L. Scrimieri, A. Serra, D. Manno, L. Calcagnile, The synergistic role of $\mathrm{pH}$ and calcination temperature in sol-gel titanium dioxide powders. Appl. Phys. A 125, 735 (2019)

33. A. Jilani, M. Shaaban, A.H. Hammad, Advance deposition techniques for thin film and coating, in Modern technologies for creating the thin-film systems and coatings (Chapter 8). ed. by N.N. Nikitenkov (IntechOpen, London, 2017)

34. W.B. Wang, A. Yanguas-Gil, Y. Yang, Chemical vapor deposition of $\mathrm{TiO}_{2}$ thin films from a new halogen-free precursor. J. Vac. Sci. Technol. A. 32, 061502 (2014)

35. L. Scrimieri, A. Serra, D. Manno, P. Alifano, S.M. Tredici, M. Calcagnile, L. Calcagnile, $\mathrm{TiO}_{2}$ films by sol-gel spin coating deposition with microbial anti-adhesion properties. Surf. Interface Anal. 51, 1351-1358 (2019)

36. D. Kim, M. Jung, K. Sangjin, H. Kim, H.J. Lee, K. Oh, M. Moon, UV-responsive nano-sponge for oil absorption and desorption. Sci. Rep. 5, 12908 (2015)

37. L. Zhao, F. Xue, B. Yu, J. Xie, X. Zhang, R. Wu, R. Wang, Z. $\mathrm{Hu}, \mathrm{S}$. Yang, J. Luo, $\mathrm{TiO}_{2}$-graphene sponge for the removal of tetracycline. J. Nanopart. Res. 17, 16 (2015)

38. M.I. Arabatzis, P. Falaras, Synthesis of porous nanocrystalline $\mathrm{TiO}_{2}$ foam. Nano Lett. 3(2), 249-251 (2003)

39. R. Hickman, E. Walker, S. Chowdhury, $\mathrm{TiO}_{2}-\mathrm{PDMS}$ composite sponge for adsorption and solar mediated photodegradation of dye pollutants. J. Water Process Eng. 24, 74-82 (2018)
40. S. MiarAlipour, D. Friedmann, J. Scott, R. Amal, $\mathrm{TiO}_{2} /$ porous adsorbents: recent advances and novel applications. J. Hazard. Mater. 341, 404-423 (2018)

41. W. Ma, Z. Lu, M. Zhang, Investigation of structural transformations in nanophase titanium dioxide by Raman spectroscopy. Appl. Phys. A 66, 621 (1998)

42. T. Aguilar, I. Carrillo-Berdugo, R. GómezVillarejo, J. Gallardo, P. Merino, J. Piñero, R. Alcántara, C. Fernández-Lorenzo, J. Navas, A solvothermal synthesis of $\mathrm{TiO}_{2}$ nanoparticles in a non-polar medium to prepare highly stable nanofluids with improved thermal properties. Nanomaterials 8(10), 816 (2018)

43. R. Alcántara, J. Navas, C. Fernández-Lorenzo, J. Martín, E. Guillén, J.A. Anta, Synthesis and Raman spectroscopy study of $\mathrm{TiO}_{2}$ nanoparticles. Phys. Status Solidi (C). 8(6), 1970-1973 (2011)

44. S. Challagulla, K. Tarafder, R. Ganesan, S. Roy, Structure sensitive photocatalytic reduction of nitroarenes over $\mathrm{TiO}_{2}$. Sci. Rep. 7, 8783 (2017)

45. N. Agoudjil, T. Benkacem, Synthesis of porous titanium dioxide membranes. Desalination 206(1-3), 531-537 (2007)

46. L. Velardi, L. Scrimieri, A. Serra, D. Manno, L. Calcagnile, Effect of temperature on the physical, optical and photocatalytic properties of $\mathrm{TiO}_{2}$ nanoparticle. SN Appl. Sci (2020)

47. Y. Geng, J. Zhang, J. Zhou, J. Lei, Study on adsorption of methylene blue by a novel composite material of $\mathrm{TiO}_{2}$ and alum sludge. RSC Adv. 8, 32799-32807 (2018)

48. A. Mohammadi, A. Karimi, Methylene blue removal using surface-modified $\mathrm{TiO}_{2}$ nanoparticles: a comparative study on adsorption and photocatalytic degradation. J. Water Environ. Nanotechnol. 2(2), 118-128 (2017)

Publisher's Note Springer Nature remains neutral with regard to jurisdictional claims in published maps and institutional affiliations.

\section{Affiliations}

\section{Luigi Scrimieri ${ }^{1} \cdot$ Luciano Velardi $^{1} \cdot$ Antonio Serra $^{1} \cdot$ Daniela Manno $^{1} \cdot$ Francesca Ferrari $^{2} \cdot$ Maria Cantarella $^{3}$. Lucio Calcagnile ${ }^{1}$}

1 CEDAD-Center of Applied Physics, Dating and Diagnostics, 3 CNR-IMM, Catania, Italy Department of Mathematics and Physics, University of Salento, Lecce, Italy

2 Department of Engineering for Innovation, University of Salento, Lecce, Italy 